\title{
Investigating Human Scale Spatial Experience
}

VILLE PAANANEN, Center for Ubiquitous Computing, University of Oulu, Finland JONAS OPPENLAENDER, Center for Ubiquitous Computing, University of Oulu, Finland JORGE GONCALVES, School of Computing and Information Systems, University of Melbourne, Australia DANULA HETTIACHCHI, School of Computing and Information Systems, University of Melbourne, Australia SIMO HOSIO, Center for Ubiquitous Computing, University of Oulu, Finland
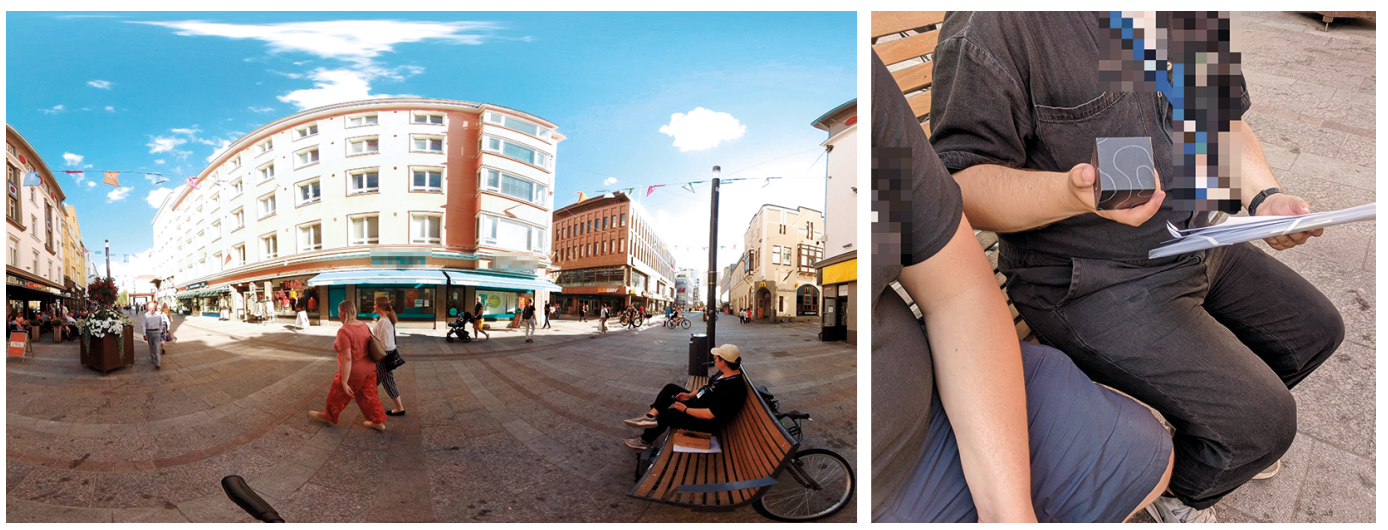

Fig. 1. Field interviews on the topic of safety using a technology speculation probe.

Spatial experience, or how humans experience a given space, has been a pivotal topic especially in urban-scale environments. On the human scale, HCI researchers have mostly investigated personal meanings or aesthetic and embodied experiences. In this paper, we investigate the human scale as an ensemble of individual spatial features. Through large-scale online questionnaires we first collected a rich set of spatial features that people generally use to characterize their surroundings. Second, we conducted a set of field interviews to develop a more nuanced understanding of the feature identified as most important: perceived safety. Our combined quantitative and qualitative analysis contributes to spatial understanding as a form of context information and presents a timely investigation into the perceived safety of human scale spaces. By connecting our results to the broader scientific literature, we contribute to the field of HCI spatial understanding.

CCS Concepts: • Human-centered computing $\rightarrow$ Empirical studies in HCI; HCI theory, concepts and models; Field studies; Interaction design theory, concepts and paradigms.

Additional Key Words and Phrases: spatial experience, architecture, interaction design

\section{INTRODUCTION}

Spatial experience is a multidisciplinary subject that can be approached through various different analytical lenses [12]. For instance, the traditional Cartesian understanding of spaces is beneficial for contexts which require mathematical precision, such as building construction. Precise geometric understanding does not, however, account for spatially formed human behaviours, such as

Authors' addresses: Ville Paananen, Center for Ubiquitous Computing, University of Oulu, Oulu, Finland; Jonas Oppenlaender, Center for Ubiquitous Computing, University of Oulu, Oulu, Finland; Jorge Goncalves, School of Computing and Information Systems, University of Melbourne, Melbourne, Australia; Danula Hettiachchi, School of Computing and Information Systems, University of Melbourne, Melbourne, Australia; Simo Hosio, Center for Ubiquitous Computing, University of Oulu, Oulu Finland. 
dwelling, interacting, or encountering [22]. These are all also pivotal in $\mathrm{HCI}$ as a form of context information $[10,12]$. Spaces can also be understood through other attributes, such as structural properties, form and design, or even personal meanings and perceptions. As a result, to deeply understand a space and its interaction affordances requires also a careful analysis of its subjective constituents [24].

The proliferation of embedded interactive technologies in the built environment calls for new methods to understand the spaces, as their complexity is beyond what can be accounted for with traditional methods $[1,27]$. Such methods are often discussed in the emerging sub-field of HCI, Human-Building Interaction (HBI). Following the technological development of ubiquitous computing and smart cities, HBI investigates our built environments as spaces where new types of interactions take place [1]. For example, HBI asks what attributes and aspects of our new built environments might HCI researchers have thus far overlooked? Further, in HCI, fully understanding people's context has always been critical to creating useful and usable applications. The ISS community specifically has embraced exploring spaces as contexts where interactions take place (see e.g. [16]). In this paper we set to explore human scale spaces through their subjective constituents, as also recommended in [24]

We investigate spatial experience on the human scale. Human scale environments focus on eye level human experiences in rooms, streets, and homes, as opposed to motorways, skyscrapers, or apartment complexes in architectural design [17]. We build toward a vision of being able to computationally capture and represent spatial experience by breaking a space down to its constituents that are subjectively meaningful for humans, i.e. spatial features. Investigating the features that together constitute space is a surprisingly unexplored topic in the scientific literature, especially on human scale. To form an understanding of this topic, we conducted two studies. In Study 1 we employed online questionnaires to form a nuanced understanding of the spatial features that people find as subjectively important in explicating a space. Second, and as a direct result of the analysis of Study 1, we conducted field interviews in authentic human scale environments to gain a deeper understanding of the top-ranked feature, perceived safety, and to speculate about the design of potential related spatial technologies.

The key contributions of this paper are:

(1) Spatial Features: We present an investigation into the distinct spatial features that can be used to understand human scale spaces.

(2) Technology Speculation: We present semi-structured interview findings regarding a single spatial feature - safety.

(3) Discussion: We place our findings in the broader context at the intersection of HCI and architecture through guidelines for developing technologies.

The first study revealed subjective presence, active involvement, and structural aspects as key themes that people build their spatial experience on. The field interviews concerning the most important individual feature - safety - uncovered further quantifiable aspects to it, such as general visibility, amount of light, and presence of others. Technology-wise, participants perceived potential not only in self-tracking and surveillance technology but also brought up the temporal dimension as an avenue to explore. Our study on spatial experience on the human scale contributes to the literature of how humans understand spaces and provides further research opportunities in the nexus of $\mathrm{HCI}$, HBI, and architecture. 


\section{RELATED WORK}

\subsection{Spatial Experience}

The subject of spatial experience is relevant to various fields. The cognitive aspects of spatial experiences are relevant in psychology, geography, architecture, urban planning, linguistics, anthropology, biology, and computer science [36]. The plurality of viewpoints these fields provide leads to a rich understanding of how humans exist and experience spatially. On the one hand, individual factors, such as person's current mood, their cultural background, and their physical abilities, have an effect on the qualities of the spatial experience. On the other hand, spatial experience is shaped by various features of the environment. To aid understanding, different models for these viewpoints have been developed, for example Montello [36] articulated architecture's effect on physical, mental, and sociocultural experiences.

In psychology, findings have shown links between the experience of space and how human brains structure information. The ability to hold internal cognitive maps of the environment has been well understood in psychology, but recently more information on the neural structure of these representations has been discovered [19]. Relevant to perception and meaning-making, taller buildings have been found to contribute negatively to psychological restoration [33]. Further, home has been found to correlate more with positive mood, and personality traits affect a person's experience of spaces [43]. And recently, using physiological and qualitative measures, the geometrical features of spaces have found to have an effect on human emotions [46]. In the field of social neuroscience, Lederbogen et al. [30] found that living in urban environments is a risk factor for social stress, which can be used to predict schizophrenia. These examples make a case for cognitive understanding of human spatiality.

Applying the research from environmental psychology in urban design, Gehl [17] focuses on the importance of movement, distance sensing, and vision in the perception of the urban environment. The phenomenological approach of understanding how we perceive spaces has been found to be relevant for architectural design [40]. In the field of proxemics, the cultural aspects have been found to correlate with interpersonal distances and how humans use and take space [20]. Further, spaces can be understood as a structure for labor, power, or social meanings [31].

These examples reveal the scope of spatial experience: the experience of spaces is truly embodied, stemming from the human body through the perceptual system, motor abilities, and cognitive functions. As social beings, humans share spaces with each other, shaping how we use spaces and what meanings we assign to them. With the rise of computer systems, however, a need to be able to describe spaces in a machine-readable format has emerged. To this end, an analytic methodology called space syntax allows to analyze urban environments as networks of distances and visibilities, and how humans contribute to place-making [22]. Following the space syntactical approach, Kuliga et al. [29] for instance evaluated spatial experiences in the Seattle Public library. Their work resulted in a syntactical set of six descriptive word pairs. These are unsafe-safe, narrow-spacious, closed-open, monotone-varied, public-private, and inaccessible-accessible.

\subsection{Spatial Experience in $\mathrm{HCI}$}

Seminal work in ubiquitous computing highlights how context has always been an important but too often overlooked aspect in application design [10]. Given how technologies that allow for applications to be built are constantly evolving, application use contexts change too. As technologies can now be built in our environments (e.g. public interactive touch screens [18]) or taken with us on the go (smartphones, augmented reality), new methods for understanding and digitizing also spatial understanding are being constantly investigated. Location-based data mining from social media $[9,25,26,52]$ now allows for large-scale data analysis. Crowdsourcing human experiences 
of places $[8,14,24,51]$ can further provide authentic experiences of spaces in the urban scale. As a particularly relevant example to our work, Goncalves et al. explored how to build a collective subjective understanding of a space using gamification and touch screens. In thier work, people played a simple game on the screens to rank-order adjectives from the English dictionary to describe their immediate surroundings [18]. While these examples are in the context of urban spaces, HCI has always recognized the need for human scale spatial understanding to support designing better applications.

On a pair of seminal papers on human scale spaces and places in HCI, Harrison and Dourish [21] and Dourish [12] brought focus to the understanding of humans' spatial dimensions and how the concepts of space and place can be used in design. While these concepts have brought new concrete tools to understand spaces, in the grander scope of HCI spatiality is also investigated as a factor in designing any types of spatial technologies (see e.g., $[1,27,28,32]$ ).

$\mathrm{HCI}$ is now seen as integral to architecture as well. Many modern spaces are equipped with tech, sensors and AI-driven solutions [1]. To highlight just some of the challenges of spatial understanding that emerge as a result of this, Kirsh [27] focuses on the notions of interaction and interfaces in such tech-augmented environments. The differences between these field run deep: "People don't read buildings the way they do HCI interfaces" [27]. The limitations of traditional interaction patterns in terms of agency, intention, and control serve as a strong argument that we need to frame our thinking in a new way when thinking about spatiality in HCI. For example, proxemics has been suggested as an effective framework for describing how movements and orientations people have with devices can inform design [3].

Perhaps most related to this article, the rapidly emerging field of HBI aims to make sense of human experiences in buildings that increasingly incorporate technologies such as artificial intelligence and new forms of interactivity through e.g. augmented reality or other ubiquitous computing tech. Specifically the human experience within such environments is a key research interest in HBI [1], which itself is positioned in the intersection of HCI and architecture. In this article we set to advance the understanding between these fields by investigating what spatial features are pivotal for constructing people's subjective experiences on human scale. Second, we provide a deeper look into speculative design for the feature that people found as most important, safety.

\section{STUDY 1: SPATIAL FEATURES AS CONSTITUENTS OF SPATIAL EXPERIENCE}

\subsection{Design}

To gain an understanding of which specific aspects (i.e. spatial features) do people find as important in describing their spatial experience, we deployed an online questionnaire to Prolific ${ }^{1}$. Prolific is crowdsourcing platform for scientific studies, known for its broad suitability for qualitative and creative tasks [39].

We were interested in deriving a list of spatial features "from scratch", i.e. letting the participants freely describe any and all features of a space they find as important in being able to characterise it. In addition to this, we asked participants about how much do they pay attention to the spaces around them in general. The questionnaire items are listed in Table 1. The demographic information was available through Prolific.

\subsection{Results}

3.2.1 Participants. We recruited 102 participants over the course of one day. Participants (39 male, 63 female; $M=34.7$ years, $S D=12.2$ years) were primarily located in the United Kingdom (83.3\%),

\footnotetext{
$1_{\text {www.prolific.co }}$
} 
Table 1. Study 1 questionnaire items.

\begin{tabular}{lll} 
No. & Question & Type \\
\hline Q1 & How do you understand the phrase "spatial experience"? & Text \\
\hline Q2 & $\begin{array}{l}\text { How often do you pay attention to the design of such spaces } \\
\text { around you, i.e. the built design of a space? }\end{array}$ & 7-point Likert (1 - Not at all often, \\
7 - Extremely often)
\end{tabular}

with a minority of participants in other countries (US $8.8 \%$, Australia $2 \%$, Ireland $2 \%$, Canada $1 \%$, India 1\%, New Zealand 1\%, Philippines 1\%). We limited participation to participants with English as the first spoken language and a minimum of 50 successfully completed tasks.

The participants' response to how much they paid attention to built spaces $(\mathrm{Q} 2)$ was $(M=3.95$, $S D=1.38)$ and to everything else $(Q 3)$ such as interaction around them was $(M=4.25, S D=0.96)$.

3.2.2 Qualitative Analysis. Next, we thematically analyzed the open-ended questionnaire items following the guidelines by Braun and Clarke [6]. We formed features based on the answers by the participants in the questionnaire item Q4. After the items were labeled with features, we grouped them into higher-level themes which reflect important spatial features, as shown in Table 2. The labeling was done by the first author, followed by discussions of the labeling among authors until a consensus was reached [35]. The three themes that were the outcome of the thematic analysis are as follows:

Subjective presence. Being in space is first and foremost an embodied experience. Experiencing the space around us is mediated by our sensory system, and space is perceived in a myriad of ways depending on the person's body, history, and culture. The importance of senses was grasped by participants: "Most important for me is to not have everything too close together, makes me feel claustrophobic and also it can't be too busy, overwhelms the senses” (female, 44). This is in line with Alexander [2], who claims that negative aspects of the space seem to present themselves more clearly than the more elusive positive aspects. This was also captured in some of our responses:

"Noise from people usually is the most offputting in a space, then objects like banging doors or chairs that grate on a floor surface. Electronic beeps or tannoys. Next would be lighting. A flickering light or too dark a space I don't like. Equally bright spotlights $n$ the wrong place, eg a hairdressers where you look up and the spotlight glare down into your eyes. Smells unless truly unpleasant are generally tolerated ok by me." (female, 45)

Structural aspects. The space around us has physical characteristics which shape our experience of the space. Darker rooms appear smaller, certain types of stone walls can seem lightweight, and an opening in a forest can feel inviting or dangerous. Aspects of natural light and sensible organization of space were important shared experiences between participants, as exemplified by one response: 
Table 2. Spatial features and their relevant themes from Study 1.

\begin{tabular}{|c|c|c|}
\hline $\begin{array}{l}\text { Subjective } \\
\text { presence }\end{array}$ & $\begin{array}{l}\text { Structural } \\
\text { aspects }\end{array}$ & $\begin{array}{l}\text { Active } \\
\text { involvement }\end{array}$ \\
\hline $\begin{array}{l}\text { Comfort } \\
\text { Feeling } \\
\text { Light } \\
\text { Perception } \\
\text { Safety } \\
\text { Senses } \\
\text { Time } \\
\text { Visual }\end{array}$ & $\begin{array}{l}\text { Accessibility } \\
\text { Color } \\
\text { Distance } \\
\text { Form/Shape } \\
\text { Furnishing } \\
\text { Layout } \\
\text { Openness } \\
\text { Scale } \\
\text { Size } \\
\text { Surroundings } \\
\text { Textures }\end{array}$ & $\begin{array}{l}\text { Activity } \\
\text { Interaction } \\
\text { Navigation } \\
\text { People }\end{array}$ \\
\hline
\end{tabular}

"Natural light, multiple view points/vistas, access/exit routes, sense of space, pattern, texture, colour" (female, 46). Further, evaluating the structural aspects of the space is essential for accessibility, as stated by a participant who had clear requirements for the structure of the space:

"I'm a wheelchair user so being aware of a sense of space is very important as I need to assess the space to determine if it is accessible. I need to look at how level the floor is, are there inclines and/or steps, are doorways wide enough, is there enough distance between furniture to get my chair through." (female, 51)

Active involvement. Being in a space is acting in a space. You can enter a space, leave the space, and function in the space. You can interact with the space, or other people in it. The social function of spaces creates an important layer of spatiality "I notice the people around me and pay attention to what people are doing in my space" (female, 34). Hall [20] emphasized the role of smells in social contexts, especially in smaller spaces, which was also present in answers, e.g.: "Smells are a very big aspect of confined spaces" (male, 46). Being able to adjust your surroundings to your liking is seen as important, allowing for a sense of freedom and agency, as stated by one participant:

"I think one of the most important feature of a spatial experience is the ability to actually be able to move around freely in that set space. While a space may have it's purpose the ability to move around and not feel trapped or encumbered is something that can change any space from being okay to great. Secondly it would be the ability to personalise said space as that also adds a touch of ownership to it, which in turn is to give someone more responsibility for looking after the space." (male, 21)

\subsection{Rank-Ordering the Spatial Features}

We wanted to understand the relative importance of the spatial features identified in the first questionnaire. For this, we deployed another questionnaire using Prolific as our source of participants. We used 25 of the most frequent (i.e. how many times they occurred in user answers after the qualitative analysis and tagging) spatial features (see Table 2). We asked the participants to rate the importance of each feature in for describing their spatial experience, using a 7-point Likert item from " 1 - Not at all important" to "7 - Extremely important." The item order was randomized for each participant.

We recruited 101 participants from Prolific using the same qualification criteria as previously. Participants were paid UK $£ 0.30$ for completing the study. The average time taken to complete the study was $3.11 \mathrm{~min}(S D=1.95 \mathrm{~min})$. We manually paid bonuses for participants who took 
longer than expected, bringing the average hourly wage above UK $£ 10$. The participants (52 male, 48 female, 1 undisclosed; $M=31.0$ years, $S D=8.9$ years) were from mostly-European countries (UK 18.8\%, Poland 16.8\%, Portugal 10.9\%, Germany 8.9\%, Greece 8.9\%, Italy 5.9\%, US 5.9\%, Spain 5\%, Hungary $4 \%$, Estonia $2 \%$, Ireland $2 \%$, Mexico $2 \%$, Sweden $2 \%$, and other countries (7\%)).

3.3.1 Results. The rating of importance resulted in the spatial features depicted in Figure 2. A Kruskal-Wallis test showed a statistically significant effect $\left(\chi^{2}=281.53, p<.001, d f=24\right)$ in the importance ranking of the spatial features. The five most important features were, in descending order, safety $(M=6.08, S D=0.98)$, cleanliness $(M=5.91, S D=1.16)$, comfort $(M=5.83, S D=1.11)$, feeling $(M=5.71, S D=1.29)$, and light $(M=5.7, S D=1.21)$. These are from the subjective presence and structural aspects themes. It is notable that the mean values of all of the features were perceived positively.

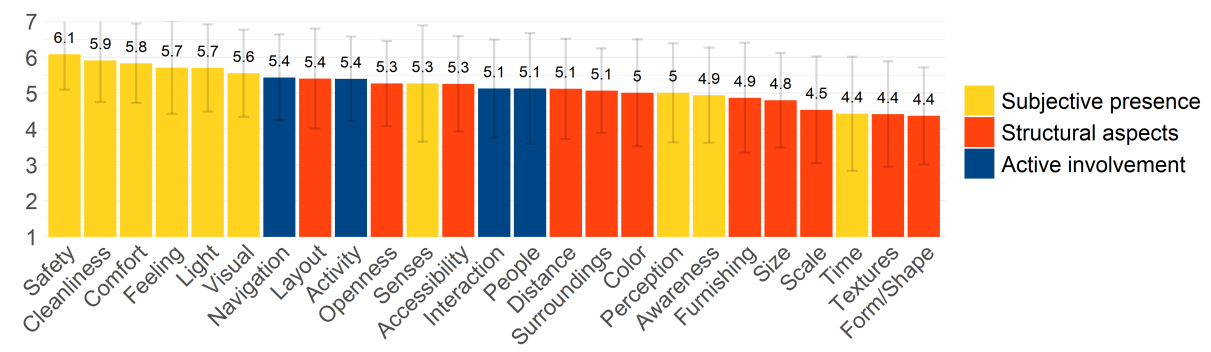

Fig. 2. The mean values of the perceived importance of spatial features arranged from least (1) to most important (7) and colored based on the thematic groups found in Study 1. Vertical lines represent the standard deviation value for each feature. "Subjective presence" was found to be generally more important than the "Structural aspects".

\section{STUDY 2: IN-SITU EXPLORATION INTO PERCEIVED SAFETY IN SPACES}

Given that safety was the highest-ranked spatial feature, we wanted to explore what makes a space (un)safe and how to potentially leverage safety as a design affordance: How to design technologies that can either capture the felt sense of safety or technologies to make spaces safer?

\subsection{Study Design}

We conducted semi-structured field interviews in different locations following Woelfer et al. [51] research on situated safety and technology usage. Using a similar approach, we did not provide the participants with our definition of safety, but we let the participants form and describe their own understanding of safety. To understand safety at different times of day and to provide a different context for the interviews and thus increase the external validity of the results [44], we conducted some of the interviews during the late evening.

Prior to the actual interview, the participants filled in a short questionnaire. The questionnaire and interview topics are shown in the Table 3. The interviews were based on the following two themes: 1) situated safety and 2) technological speculation. The questions $3-6$ are quantitative measures for understanding situated safety (see e.g. [42]) and the rest of the questions provide qualitative insights in the interviews. HCI as a research field is always looking into the future of developing new technologies, and to this end, speculative design has been proven to be one method for obtaining future visions for design [13]. In this vein, to provoke the participants' imagination for technology speculation and data collection, we used a speculative design method [13, 23, 48] 
where a physical prop was given to the participants to come up with ways it can capture or improve their sense of safety. We used a simple black cube as a prop, as depicted on the right in Figure 1. We hoped this approach would also be helpful toward our own long-term goal of being able to computationally capture and convey spatial experience. We note that such a prop in speculative design is not meant as a specific device that people design applications for. Rather, its role is a "magic device" that gets people started thinking without design or other mental constraints, as is evident from our results too (discussed later).

The interviews were conducted in the country's native language to ensure participants could express their experiences in as much detail as possible. The interviews were recorded, transcribed, and translated for analysis by the first author. The analysis followed the same thematic method proposed by Braun and Clarke [6] as in the open-ended questions in Study 1.

\subsection{Participants and Locations}

We used purposive sampling [15] to select participants from specific locations. We interviewed 19 participants at different times of day and in different locations, and after review we excluded one participant due to incoherent responses, leaving us with 18 participants to focus on for analysis The interviews lasted between 4 and 20 minutes $(M=7 \mathrm{~min} 35 \mathrm{~s}, S D=4 \mathrm{~min} 10 \mathrm{~s})$. The participants experience with perceived safety varied, which is shown in the interview durations as well. The participants were between 19 and 72 years old $(M=34.1, S D=18.4$ years), 8 participants $(44 \%)$ were male, 9 were female, and 1 non-binary. The participants were rewarded with a $6 €$ coffee voucher for the interview. The interviews took place in four different locations around the city center, each during the day (around $1 \mathrm{pm}$ ) and in the late evening (around $9 \mathrm{pm}$ ), resulting in eight unique situations. Two of the locations were indoors (a café and a shopping mall) and two were outdoors (city center and a park). The study was approved by the institution's IRB and we obtained permission to conduct interviews in these different locations.

\subsection{Results}

4.3.1 Questionnaire results. The questionnaire results show that the participants $(N=18)$ feel relatively safe overall as depicted in Figure 3. There was a significant effect $(t(24.2)=2.77, p=.01)$ in safety during the day $(M=6.17, S D=0.62)$ compared to safety during the night $(M=5.22$, $S D=1.31$.

While the sample size of the interviews does not allow for a thorough quantitative analysis, it served as useful background for the interviewees and their subjective experiences.
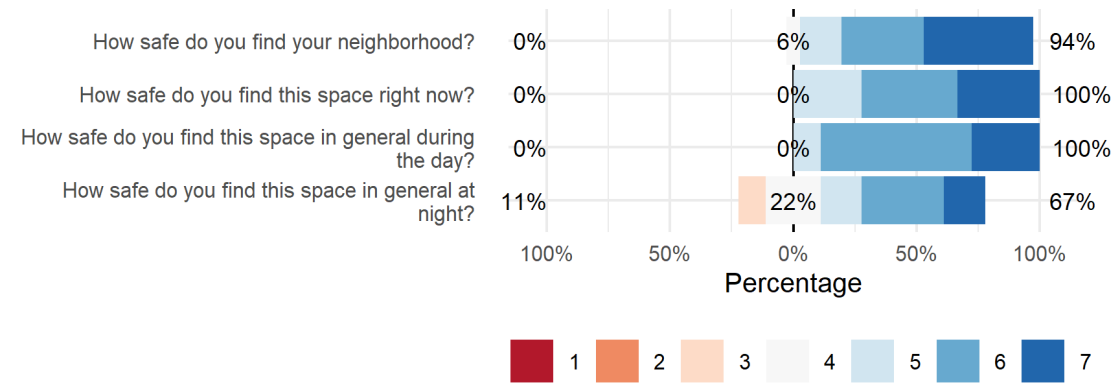

Fig. 3. The questionnaire aggregate results on a 7-point Likert scale ( 1 extremely unsafe - 7 extremely safe) 
Table 3. Interview items. Note that item 5 depends on the current time of day: during the day, we asked about the night, and vice versa.

\begin{tabular}{|c|c|c|c|}
\hline Phase & Topic & Questions & Type \\
\hline Introduction & Intro & Introduction and consenting to the study & Agreement \\
\hline \multirow{6}{*}{$\begin{array}{l}\text { Pen-and-paper } \\
\text { questionnaire }\end{array}$} & \multirow{2}{*}{$\begin{array}{l}\text { Background } \\
\text { questions }\end{array}$} & 1. Age & Text \\
\hline & & 2. Gender & Text \\
\hline & \multirow{8}{*}{$\begin{array}{l}\text { Situated } \\
\text { safety }\end{array}$} & $\begin{array}{l}\text { 3. How safe do you find this space right } \\
\text { now? }\end{array}$ & $\begin{array}{l}\text { 7-point Likert (ex- } \\
\text { tremely unsafe - } \\
\text { extremely safe) }\end{array}$ \\
\hline & & $\begin{array}{l}\text { 4. How safe do you find this space in gen- } \\
\text { eral? }\end{array}$ & $\begin{array}{l}\text { 7-point Likert (ex- } \\
\text { tremely unsafe } \quad- \\
\text { extremely safe) }\end{array}$ \\
\hline & & $\begin{array}{l}\text { 5. How safe do you find this space [at } \\
\text { night/during the day]? }\end{array}$ & $\begin{array}{l}\text { 7-point Likert (ex- } \\
\text { tremely unsafe } \quad- \\
\text { extremely safe) }\end{array}$ \\
\hline & & $\begin{array}{l}\text { 6. How safe do you find your neighbor- } \\
\text { hood? }\end{array}$ & $\begin{array}{l}\text { 7-point Likert (ex- } \\
\text { tremely unsafe } \quad- \\
\text { extremely safe) }\end{array}$ \\
\hline \multirow{7}{*}{ Recorded interview } & & 7. Do you come here often? & Text \\
\hline & & $\begin{array}{l}\text { 8. Have you ever avoided this space? } \\
\text { Why? }\end{array}$ & Text \\
\hline & & $\begin{array}{l}\text { 9. What contributes positively to your } \\
\text { feelings of safety in this space right now? } \\
\text { Why? What about in general? }\end{array}$ & Text \\
\hline & & $\begin{array}{l}\text { 10. What contributes negatively to your } \\
\text { feelings of safety in this space right now? } \\
\text { Why? What about in general? }\end{array}$ & Text \\
\hline & \multirow{3}{*}{$\begin{array}{l}\text { Technology } \\
\text { speculation }\end{array}$} & $\begin{array}{l}\text { 11. Here we have a magic device. Us- } \\
\text { ing your imagination without limitations, } \\
\text { how could this piece of technology cap- } \\
\text { ture your sense of safety? }\end{array}$ & Text \\
\hline & & $\begin{array}{l}\text { 12. How could the device improve your } \\
\text { sense of safety? }\end{array}$ & Text \\
\hline & & $\begin{array}{l}\text { 13. If this magic device were to exist, in } \\
\text { what situation would you find this tech- } \\
\text { nology useful? }\end{array}$ & Text \\
\hline Wrapping up & & 14. Anything else that comes to mind? & Text \\
\hline Follow-up study & $\begin{array}{l}\text { Follow-up } \\
\text { study }\end{array}$ & $\begin{array}{l}\text { 15. Do you want to take part in a follow- } \\
\text { up study? If yes, please write down your } \\
\text { email address. }\end{array}$ & Agreement \\
\hline
\end{tabular}

4.3.2 Interviews on Feeling of Safety. Overall, aspects of the perception of safety are experienced very differently across participants: some focused on the physical aspects, some on the mental aspects, one talked about bicycle traffic, one talked about the higher-level concept of safety in terms of trust. Combined, these interviews highlighted several important aspects in the perception of 
safety. Safety was partially affected by the space through good visibility, the presence of people, and person's own subjective experiences.

Visibility in the surroundings was a factor that came up in multiple interviews, and it was found to be connected to the amount of light. Space that affords long sightlines and sufficient lighting improves the feeling of safety. In short, light brings things to light, which was expressed by an interviewee as: "Overall, I find that light affects safety. It brings the feeling that I can see." (male, 27)

Although we hoped to extensively also interview people at night, we found this to be rather difficult: nighttime was clearly perceived as less safe, perhaps due to the darkness, and the approaching researchers were, in some sense, not a compelling prospect to engage with. Curiously, during the night the participants seemed to find the design speculation task to be quite difficult in comparison to daytime.

Characteristics of people, whether self or others, were clearly an important factor of safety in space. Several participants explicitly stated, and it was seen in the interview answers as well, that gender plays a role in the perceived safety. Accordingly, one participant noted that:

"As a man I don't really feel that kind of threat. Or that there's areas or times of days when you feel threat. Or even during the day" (male, 27).

In terms of physical aspects, two participants stated that a persons' size matters as well: taller people do not find safety as much of an issue as shorter people. This might be due to the implication of size to physical strength. An interesting insight was that even the demography of the people in the space affects your safety: "If the place is full of 40-yo men, a 20-yo woman is seen a bit differently, so the demography matters. Here there's an even mix of all kinds of people" (non-binary, 32). The space is not evaluated only through its physical dimensions, but also who is present, and how similar the others are to yourself.

Information affects the experience of safety as well. Social media and news were found to be one factor. The "constant feed" of news affects how you perceive spaces, and for example, one participant noted that when news of a bomb threat came out, he avoided the space for some time. Even though we did not set out to purposefully focus on the effect of the COVID-19 pandemic, it came up in almost every interview, in one way or another. Some did not find the pandemic to affect the felt safety of the given space too much, but many people were concerned about the general hygiene of public spaces. A café shift manager focused on hygiene as the first aspect of safety. It is notable though that at the time of the interviews the city had a very low number of daily COVID-19 cases and there were no restrictions on, e.g., opening hours or other business limitations.

The interviews uncovered distinct potentially quantifiable aspects to safety. These include visibility in a space, size of the space, amount of light, time of day, amount of other people, physical aspects of other people, gender of self and others, and presence of authorities. Factors such as ingesting the news feed are more difficult to quantify, requiring an understanding of the topic and its effect on the person. The quantified features allow for the development of safety-aware systems with greater accuracy as compared to one without an understanding of human factors.

Our interview findings with the previous studies lead to a vertical slice of spatial understanding. The result of this is shown in Figure 4. Explication of these features allows for an understanding of several levels of abstraction. The themes found in the Study 1 carry over into the lower-level features and it is notable that in the case of safety, which was themed as "subjective presence," its features are not limited to that theme. In other words, the spatial experience consists of interconnected features affecting each other.

4.3.3 Design speculation. The task of speculating how technology could be developed to improve safety brought up interesting insights into how people experience spaces in terms of safety. The results from the design speculation can be described in the following categories: 


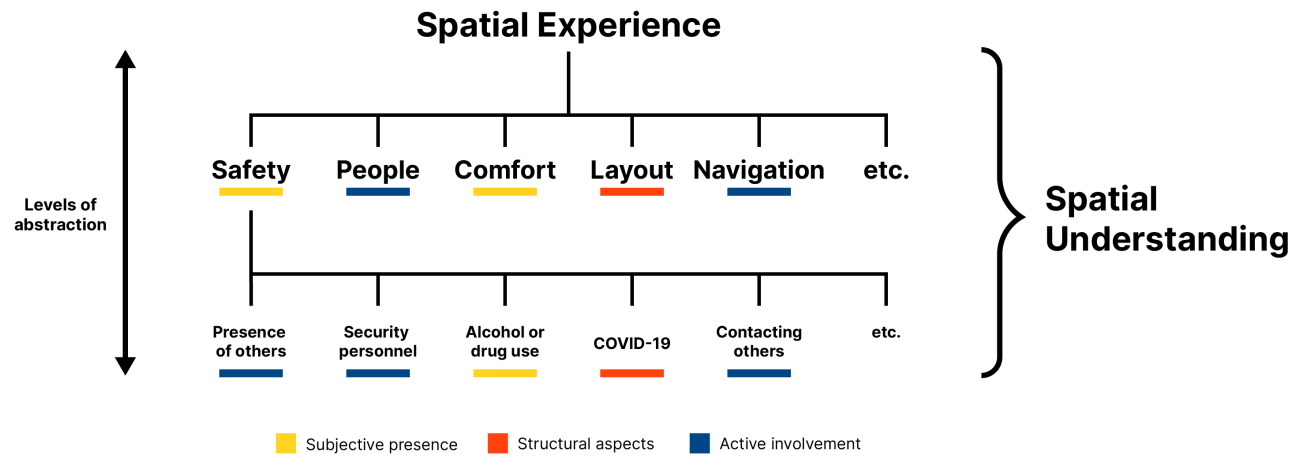

Fig. 4. Overview of spatial understanding. The various spatial features are color coded based on the themes found in the first study.

Physiological and psychological measurement. The participants considered heart rate, hormone levels, adrenaline levels, blood sampling, microexpressions, speech patterns, and anxiety levels to serve as a predictor of perceived safety, or more accurately, feelings of lack of safety. This was expressed by participants as "Heart rate and blood samples and hormone measurements. So the physiological aspects of safety. States of fear, stress reactions" (male, 27) and "It could see that I am nervous. So it could watch my faces what is my reaction, way of talking, heart rate" (male, 26).

However, participants found difficulties with measuring these aspects reliably: "First, heart rate, but it might be unreliable [to measure]. There are cafés around here, and at least for me, coffee raises my heart rate. Maybe also level of anxiousness, there's probably something you can monitor. But I'm anxious normally so it might not be something to do with safety." (non-binary, 32) and: "Mental stuff you can't really measure. Or at least, is it meaningful to measure them, can you compare psychological or subjective experiences? Can you form any kind of data out of them?" (male, 27). These responses indicate that the chosen measurement method needs consider possible confounding factors to reflect the actual feeling of safety.

Environment assessment. The surrounding environment, whether space or other people, was seen as beneficial to assess. Temporal aspects were brought up as well in terms of the past: "What kind of people are around you, and what has happened before." (female, 20), and the future: "A camera which could see the future, maybe, if it's safe there. So you could know if a place is safe before you go there" (female, 26). One participant, who worked as an event producer, found use for counting masses to ensure safety:

"For example in shopping malls you could count the amount of people, which would help to control the masses. Not so much as who are in the space, but how many, and does it form a mass of people. It's a different thing if there's a lot of small groups or a mass of people." (female, 24)

Communication device. Overlapping with the existence of mobile phones, the ability to communicate was easily grasped and seen as very useful. Being able to communicate was a method to avoid being alone in a situation. The communication can be towards other people, or authorities, such as staff or security personnel. These types of devices were seen to increase person's autonomy, as exemplified by one participant: 
"It could send a message to authorities if I am attacked. But haven't thought about using one of these. If you would use it, you might learn to think that you don't need to survive a dangerous situation alone." (male, 61).

Self-adjustment tool. The ability of the technology to guide and advise was seen as beneficial for some. Some even found use in subliminal control, where the technology could adjust your thoughts or guide your paths towards safer areas, as stated by one interviewee:

"If it could do anything, then maybe it could read my thoughts and guide me to safer routes. To make safer choices for me. Or if it could talk it could advise me." (male, 37)

\section{DISCUSSION}

\subsection{Human Scale Spatial Experience}

In this article we set to advance the collective understanding of the individual features that people find as important in constructing their overall subjective understanding of a space. As artificial intelligence, augmented reality and other ubicomp technologies in our built environments proliferate, such contextual understanding is an evergreen and high-impact research direction in HCI [1]. The way how humans appropriate and subjectively create meanings for spaces makes their investigation far more complex than simply measuring their physical characteristics [12]. For example, the presence of other people in a space is a factor in how the space is experienced. For some, such presence means a threat and for some others, it could mean safety. Yet, it is a feature that we must learn to model, should we want to create methods for HCI to understand spaces better. To draw in influences from the field of architecture, all this echoes the statement by Pallasmaa, where spaces are experienced in a holistic fashion:

"Indeed, the immediate judgment of the character of space calls for our entire embodied and existential sense, and it is perceived in a diffuse, peripheral and unconscious manner rather than through precise, focused and conscious observation." [41]

In our study the features we found as the most important (e.g. safety, cleanliness, comfort, feeling, and light) are partially in line with the syntactical set of Kuliga et al.'s word pairs [29]. The word pairs align well with the theme of "structural aspects", except "safe-unsafe", which belongs to the theme of "subjective presence". Also, the themes resulting from our thematic analysis coincide with space syntactical categorization of three interconnected aspects: physical, spatial and social [22]. Consequently, our findings support the set of themes in the emergence of HBI: physical-material, spatial-configurational, and social-cultural [1].

\subsection{Toward Safety-Aware Technology}

Safety emerged as the most salient spatial feature that people found as important in experiencing spaces. Prior work on what induces fear in an urban context documented darkness, contexts of potential accident or theft, and unfamiliar male presence. Conversely, factors reducing fear included: personal indoor environment, my local, access to responsive authority, presence of friends/coworkers/family, and personal device engagement [4]. In line with these results, our participants found their home environment safer than public spaces, which is understandable through concepts like defensible space, which elucidates how the person's control over the design of their dwelling can afford better protection [38]. In contrast, people have less control over the qualities of public spaces.

To build on the added understanding on safety, we introduced an element of technology speculation here to hypothesize the ways technology could be used to improve and capture safety. We gained insights into technology potential in different age groups. Where younger people seemed to be more positive towards using new technologies for their safety, older people did not find the 
technology speculation to provide many useful outcomes. In this sense, the role of technology is notable, as the digital nativity places people in different skill levels. Anecdotally, one senior citizen felt that they do not need to be concerned about safety or technologies to improve it: "No I don't believe in that kind of stuff. In this age, I don't need anything like that" (female, 72).

Technology resistance is always inevitable. Even so, given how safety of spaces clearly is a major element, it only makes sense to explore how to design with that in mind. In our Study 2, the participants had wildly differing aspects of what affects overall safety and even to what safety means to them (physical, mental, traffic, etc.) A lot of technologies already focus on e.g. making traffic safer, but perhaps there is an interesting opportunity here to explore how to make spaces psychologically safer through technologies? Here, ideas such as knowing "what kind of people" are around you or awareness of the history of a place could be worth investigating.

\subsection{Developing Spatial Technology}

We outlined different facets of spatial experience and technological speculations of spatial systems. An important consideration is, then, where could one apply such captured spatial experience beyond academic knowledge? Using the spatial understanding as the basis, interaction design can provide new opportunities for future technologies. All this added experiential knowledge is useful in designing future spatial technologies. For instance, when we sought to dive deeper into understanding the perceptions of safety specifically, our technology speculation process resulted in four groups: physiological and psychological measurement, environment assessment, communication device, and self-adjustment tool. Already for these four groups alone, we can see a lot of potential for developing new spatial technologies. It is not difficult to imagine a telepresence solution that lets people explore spaces in far more detail than is currently possible prior to actually entering the space. Or, imagine a mobile solution that increases people's autonomy in an automated way and keep the owner safe in different potentially dangerous situations, as was suggested among our speculation.

But before such technology can be designed, we argue there is a pressing need for more agile ways to capture the subjective constituents of spaces. Existing approaches for gathering spatial experiences provide only limited expressivity for users, as the approaches focus on eliciting a limited number of factors from the crowd. As an example, Google Maps Places features star ratings, user-contributed images, and textual comments for places. The simple star rating system misses the finer-grained subjective impressions by people, based on all their senses. Further, this data is aggregated on a scale that is focused on locations and businesses, but not on the human scale, in smaller spaces within a location. In this article, we conducted a type of "manual process" on curating this information. Based on that alone, we can propose certain guidelines for spatial technology developers.

\subsection{Guidelines for Developing Spatial Technology}

Synthesizing our findings and experiences in the studies, we propose certain overarching guidelines for designing spatial technologies.

Account for varying subjective experience. Spaces are experienced in the first point of view, and the subjective understanding and feelings of the surroundings are accordingly varied. Factors such as one's body, history, and cultural background all affect the subjective understanding of a human scale environment. In our study we found some participants emphasizing spaciousness, while some focused on the sensorial qualities and how they are affected by them. In other words, different people focus on different aspects of space, but they also can experience the same aspect in different ways. These subjective viewpoints are a challenge that must be taken into account or at least recognized as potential factors in designing spatial technology. 
Acknowledge different dimensions of spatiality. How does the technology support and affect the themes of spatiality found in our study: subjective presence, structural aspects, and active involvement? The themes provide practical lenses through which technologies can be further examined already prior to implementation. Further, these themes can act as a starting point for developing new technologies or cross-discipline communication, as they cover the wide and nuanced range of human spatiality.

Facilitate diversity. Accounting for diverse users is not a novel idea. However, with spatial technologies, there are distinct types of considerations for facilitating diverse users. As exemplified in Study 1, a person using a wheelchair has a different subjective experience of the space in comparison to an able-bodied person, even if the physical aspects, i.e. accessibility, would be perfectly accounted for. Similarly, in Study 2 we also found that female participants experienced nighttime as being more dangerous compared to males, leading to the female forming habits they exhibit in those spaces for maintaining safety. We also uncovered how visibility affected a person's safety perceptions, which can be understood on one hand through the person's visual capabilities, but on the other hand in the quality of lighting in the space. These findings highlight how users have different capabilities for e.g. spatial navigation, cognitive assessments, and sensorial experiences. In a way, this paves the way for spatial accessibility in the subjective dimension, and we argue that the personal experiences of the individual can be considered as design materials when creating future spatial technologies.

Support human safety, autonomy, and privacy. Spatial technology should support users' safety, autonomy, and privacy. Related to this, in the interviews we found visibility to be important for the feeling of safety. This is relevant for example for augmented reality applications, where obstructions by the user interface can limit visibility. Further, participants found great use from being able to contact others when a space feels unsafe, and thus in one way bringing others into our spatial realm even remotely has its uses. This is in line with Sloterdijk [47]: "Someone on the telephone - that is always a distant life rendered present." However, we also found people valuing their autonomy high in public spaces, which requires careful consideration of the values of spatial technology. Putting our results together, however, safety autonomy and privacy seem to be core values for spatial technology that should be always considered carefully.

\subsection{Interactions in Architecture}

Given the centric role of context in designing applications [10], spatial experiences should be at the core of the design process when developing solutions for the human scale. In architectural design, these same arguments have been echoed by e.g. Takeuchi [49]: the introduction of ubiquitous systems into architecture benefits from deeper integration, allowing HCI tools and methods to influence the built environment. We argue that interactive spaces, media architecture, HCI, and the built environment can come together more meaningfully through understanding human perceptions of spaces. For instance, in our work the structural aspects and active involvement are intertwined: when we create spaces, we shape ourselves in return. Indeed, the symbiotic relationship between humans and spaces is inseparable. "Space ... belongs to humanity like a limb" stated Bollnow [5]. Developments like organic architecture [37], sprayable user interfaces [50], and spatial augmented realities [45] provide new interaction potentials for being in a space.

Although interaction design often focuses on visual and tactile senses, the benefit of multisensorial understanding is acknowledged, as highlighted by the theme of subjective presence in our findings. Related to this, e.g. the OSpace project by Dmitrenko et al. [11] studied the possibilities of an olfactory interaction space with a scent-delivery system. Unique to the sense of smell, interaction space is inseparable from architectural space while being highly subjective since scents are closely linked to memories and personal meanings [34]. In terms of touch, Brauner et al. [7] researched 
furniture-embedded sensors for textile interactions and found that users appreciate the hedonic qualities and attractiveness over functional purposes. While modern devices provide only limited tactility, there is potential for many of the highly subjective senses and experiences of humans, as they can alter our perception of time and space and be used as design materials in architecture.

\subsection{Limitations and Future Work}

We acknowledge limitations in our study. First, in the second study we focused on the experience of safety in a single city. As spatial experiences are subjective and partially formed by culture [20], we cannot claim our results to generalize well across all geographical areas or cultures. Second, we note that our studies were conducted during the COVID-19 pandemic. This might affect the results, as in the second study the COVID-19 pandemic was present in the participants' answers. For instance, a participant noted good hygiene in a café specifically as a pandemic-related concern, which suggests that the pandemic has shifted the perceptions of safety in some spaces. The first study was more generic in nature, and we did not notice any indication or mentions of the pandemic having an effect on what constituents of a space people perceive to matter. Third, in the studies, we did not use validated scales. Our primary goal was to explore open-endedly people's perceptions of what are the key spatial features that help people form an understanding of space. We were unable to find suitable questionnaires for this, and moreover, the analysis is mostly qualitative. We argue that the questionnaire was successful for this purpose, and hope to see novel scales emerge for spatial understanding e.g. in the field of Human-Building Interaction.

The ongoing COVID-19 pandemic is not only a potential limitation in study validity but presents a research opportunity. What is the role of the pandemic in spatial safety perceptions? This is related to cultural diversity as well. The pandemic is being treated by public health organizations differently across different regions, further amplifying the effect it may have on the perceptions of individuals. Replicating our study in different locations would be beneficial in learning how subjective constituents of spaces differ across different cultures and regions, and how these differences interact with pandemic measures by authorities. Further research could also investigate ways to weave the added knowledge of how humans perceive spaces into interaction design on the human scale. To this end, our own ongoing work focuses on building a bespoke mobile crowdsourcing solution that can produce and aggregate subjective data on spatial constituents of arbitrary spaces with geofencing and experience sampling. Doing so, we hope to contribute a method to form a kind of subjective spatial experience snapshot, which can then be explored with interaction designers as contextual knowledge for new applications and situated services.

\section{CONCLUSION}

We presented a two-part study on spatial experience. Our work serves as a step towards a better understanding of human scale spatial experiences to supplement prior literature focused on the larger level of cities and urban environments. The analysis of the subjective spatial features revealed three spatial themes (subjective presence, structural aspects, active involvement) and five important features (safety, cleanliness, comfort, feeling, and light). We found that the visibility, presence of others, and subjective experiences are major constituents of perceived safety. Design speculation resulted in four categories (physiological and psychological measurement, environmental assessment, communication device, and self-adjustment tool) and insights on how technology could be developed for safety-aware systems. Our work represents a vertical slice of spatial experiences resulting in a subjective explication, providing new grounds for spatial research in HCI and HBI. Further work on spatial experiences should take into account the various aspects of being in spaces, and how they are experienced on the human scale. 


\section{ACKNOWLEDGMENTS}

This research is connected to the GenZ strategic profiling project at the University of Oulu, supported by the Academy of Finland (project number 318930), and CRITICAL (Academy of Finland Strategic Research, 335729). Part of the work was also carried out with the support of Biocenter Oulu, spearhead project ICON. We would also like to thank the reviewers for providing valuable feedback in the paper review process.

\section{REFERENCES}

[1] Hamed S. Alavi, Elizabeth F. Churchill, Mikael Wiberg, Denis Lalanne, Peter Dalsgaard, Ava Fatah gen Schieck, and Yvonne Rogers. 2019. Introduction to Human-Building Interaction (HBI): Interfacing HCI with Architecture and Urban Design. ACM Transactions on Computer-Human Interaction 26, 2 (March 2019), 6:1-6:10. https://doi.org/10.1145/3309714

[2] Christopher Alexander. 1974. Notes on the synthesis of form. Havard University, Cambridge (Mass.).

[3] Till Ballendat, Nicolai Marquardt, and Saul Greenberg. 2010. Proxemic interaction: designing for a proximity and orientation-aware environment. In ACM International Conference on Interactive Tabletops and Surfaces - ITS '10. ACM Press, Saarbr\&\#252;cken, Germany, 121. https://doi.org/10.1145/1936652.1936676

[4] Jan Blom, Divya Viswanathan, Mirjana Spasojevic, Janet Go, Karthik Acharya, and Robert Ahonius. 2010. Fear and the city: Role of mobile services in harnessing safety and security in urban use contexts. In Conference on Human Factors in Computing Systems - Proceedings, Vol. 3. ACM Press, New York, New York, USA, 1841-1850. https: //doi.org/10.1145/1753326.1753602

[5] Otto Bollnow. 2021. Human Space. Mimesis International, Sesto San Giovanni, Italy.

[6] Virginia Braun and Victoria Clarke. 2006. Using thematic analysis in psychology. Qualitative Research in Psychology 3 (2006), 77-101. https://doi.org/10.1191/1478088706qp063oa

[7] Philipp Brauner, Julia van Heek, Martina Ziefle, Nur Al-huda Hamdan, and Jan Borchers. 2017. Interactive FUrniTURE: Evaluation of Smart Interactive Textile Interfaces for Home Environments. In Proceedings of the 2017 ACM International Conference on Interactive Surfaces and Spaces. ACM, Brighton United Kingdom, 151-160. https://doi.org/10.1145/ 3132272.3134128

[8] Olga Chesnokova, Mario Nowak, and Ross S. Purves. 2017. A crowdsourced model of landscape preference. Leibniz International Proceedings in Informatics, LIPIcs 86, 19 (2017), 1-13. https://doi.org/10.4230/LIPIcs.COSIT.2017.19 ISBN 9783959770439.

[9] Fernanda de Oliveira Capela and Jose Emmanuel Ramirez-Marquez. 2019. Detecting urban identity perception via newspaper topic modeling. Cities 93, April (2019), 72-83. https://doi.org/10.1016/j.cities.2019.04.009 Publisher: Elsevier.

[10] Anind K. Dey. 2001. Understanding and Using Context. Personal and Ubiquitous Computing 5, 1 (Jan. 2001), 4-7. https://doi.org/10.1007/s007790170019

[11] Dmitrijs Dmitrenko, Emanuela Maggioni, and Marianna Obrist. 2017. OSpace: Towards a Systematic Exploration of Olfactory Interaction Spaces. In Proceedings of the 2017 ACM International Conference on Interactive Surfaces and Spaces ACM, Brighton United Kingdom, 171-180. https://doi.org/10.1145/3132272.3134121

[12] Paul Dourish. 2006. Re-space-ing place: "place" and "space" ten years on. In Proceedings of the ACM Conference on Computer Supported Cooperative Work, CSCW. Association for Computing Machinery, New York, NY, USA, 299-308. https://doi.org/10.1145/1180875.1180921

[13] Anthony Dunne and Fiona Raby. 2013. Speculative everything: Design, fiction, and social dreaming. The MIT Press, United States. https:/doi.org/10.1093/jdh/epv001 ISSN: 0952-4649 Publication Title: Speculative Everything: Design, Fiction, and Social Dreaming.

[14] Hinnerk Eifeldt. 2019. Supporting urban air mobility with citizen participatory noise sensing: A concept. In The Web Conference 2019 - Companion of the World Wide Web Conference, WWW 2019. Association for Computing Machinery, New York, NY, USA, 93-95. https://doi.org/10.1145/3308560.3317059

[15] Ilker Etikan. 2016. Comparison of Convenience Sampling and Purposive Sampling. American fournal of Theoretical and Applied Statistics 5, 1 (2016), 1. https://doi.org/10.11648/j.ajtas.20160501.11

[16] Andreas Fender and Jörg Müller. 2019. SpaceState: Ad-Hoc Definition and Recognition of Hierarchical Room States for Smart Environments. In Proceedings of the 2019 ACM International Conference on Interactive Surfaces and Spaces. ACM, Daejeon Republic of Korea, 303-314. https://doi.org/10.1145/3343055.3359715

[17] Jan Gehl. 2010. Cities for people. Island Press, Washington. ISSN: 07310455 Publication Title: Places.

[18] Jorge Goncalves, Simo Hosio, Denzil Ferreira, and Vassilis Kostakos. 2014. Game of words: tagging places through crowdsourcing on public displays. In Proceedings of the 2014 conference on Designing interactive systems. ACM, Vancouver BC Canada, 705-714. https://doi.org/10.1145/2598510.2598514 
[19] Roddy M. Grieves and Kate J. Jeffery. 2017. The representation of space in the brain. Behavioural Processes 135 (Feb. 2017), 113-131. https://doi.org/10.1016/j.beproc.2016.12.012

[20] Edward Twitchell Hall. 1969. The hidden dimension: man's use of space in public and private. Doubleday, New York. https://oula.finna.fi/Record/oula.328721

[21] Steve Harrison and Paul Dourish. 1996. Re-place-ing space: The roles of place and space in collaborative systems. In Proceedings of the ACM Conference on Computer Supported Cooperative Work. Association for Computing Machinery, New York, NY, USA, 67-76.

[22] B Hillier. 2007. Space is the Machine. A configurational Theory. Space Syntax, London, United Kingdom. http: //discovery.ucl.ac.uk/49843/

[23] Steve Howard, Jennie Carroll, John Murphy, and Jane Peck. 2002. Using 'endowed props' in scenario-based design. In ACM International Conference Proceeding Series, Vol. 31. ACM Press, New York, New York, USA, 1-9. https: //doi.org/10.1145/572020.572022

[24] Yen Chia Hsu, Michael Tasota, Jennifer Cross, Beatrice Dias, Paul Dille, Randy Sargent, Ting Hao Huang, and Illah Nourbakhsh. 2019. Smell Pittsburgh: Community-empowered mobile smell reporting system. In International Conference on Intelligent User Interfaces, Proceedings IUI. Association for Computing Machinery, New York, NY, USA, 65-79. https://doi.org/10.1145/3301275.3302293_eprint: 1810.11143.

[25] Kee Moon Jang and Youngchul Kim. 2019. Crowd-sourced cognitive mapping: A new way of displaying people's cognitive perception of urban space. PLoS ONE 14, 6 (2019), 1-18. https://doi.org/10.1371/journal.pone.0218590 Publisher: Public Library of Science.

[26] Andrew Jenkins, Arie Croitoru, Andrew T. Crooks, and Anthony Stefanidis. 2016. Crowdsourcing a collective sense of place. PLoS ONE 11, 4 (April 2016), e0152932. https://doi.org/10.1371/journal.pone.0152932 Publisher: Public Library of Science.

[27] David Kirsh. 2019. Do architects and designers think about interactivity differently? ACM Transactions on ComputerHuman Interaction 26, 2 (April 2019), 1-43. https://doi.org/10.1145/3301425 Publisher: Association for Computing Machinery.

[28] Peter Gall Krogh, Marianne Graves Petersen, Kenton O’Hara, and Jens Emil Grønbæk. 2017. Sensitizing concepts for socio-spatial literacy in HCI. In Proceedings of the 2017 CHI Conference on Human Factors in Computing Systems, Vol. 2017May. Association for Computing Machinery, New York, NY, USA, 6449-6460. https://doi.org/10.1145/3025453.3025756

[29] Saskia Kuliga, Ruth Conroy Dalton, and Christoph Hölscher. 2013. Aesthetic and emotional appraisal of the Seattle public library and its relation to spatial configuration. In 2013 International Space Syntax Symposium. Sejong University Press, Sejong. ISBN: 9788986177213.

[30] Florian Lederbogen, Peter Kirsch, Leila Haddad, Fabian Streit, Heike Tost, Philipp Schuch, Stefan Wüst, Jens C. Pruessner, Marcella Rietschel, Michael Deuschle, and Andreas Meyer-Lindenberg. 2011. City living and urban upbringing affect neural social stress processing in humans. Nature 474, 7352 (June 2011), 498-501. https://doi.org/10.1038/nature10190

[31] H. Lefebvre. 1991. The production of space. Blackwell Publishing, Oxford. https://doi.org/10.2307/490789 ISSN 04353684 Publication Title: The production of space.

[32] Laura Lentini and Françoise Decortis. 2010. Space and places: When interacting with and in physical space becomes a meaningful experience. Personal and Ubiquitous Computing 14, 5 (2010), 407-415. https://doi.org/10.1007/s00779-0090267-y

[33] Pall J. Lindal and Terry Hartig. 2013. Architectural variation, building height, and the restorative quality of urban residential streetscapes. Journal of Environmental Psychology 33 (March 2013), 26-36. https://doi.org/10.1016/j.jenvp 2012.09.003

[34] Emanuela Maggioni, Robert Cobden, Dmitrijs Dmitrenko, Kasper Hornbæk, and Marianna Obrist. 2020. SMELL SPACE: Mapping out the Olfactory Design Space for Novel Interactions. ACM Transactions on Computer-Human Interaction 27, 5 (Aug. 2020), 1-26. https://doi.org/10.1145/3402449

[35] Nora McDonald, Sarita Schoenebeck, and Andrea Forte. 2019. Reliability and Inter-rater Reliability in Qualitative Research: Norms and Guidelines for CSCW and HCI Practice. Proceedings of the ACM on Human-Computer Interaction 3, CSCW (Nov. 2019), 1-23. https://doi.org/10.1145/3359174

[36] Daniel R. Montello. 2014. Spatial Cognition and Architectural Space: Research Perspectives. Architectural Design 84, 5 (2014), 74-79. https://doi.org/10.1002/ad.1811_eprint: https://onlinelibrary.wiley.com/doi/pdf/10.1002/ad.1811.

[37] Sara Nabil, Thomas Plötz, and David S. Kirk. 2017. Interactive Architecture: Exploring and Unwrapping the Potentials of Organic User Interfaces. In Proceedings of the Eleventh International Conference on Tangible, Embedded, and Embodied Interaction. ACM, Yokohama Japan, 89-100. https://doi.org/10.1145/3024969.3024981

[38] Oscar Newman. 1996. Creating Defensible Space. Technical Report. Institute for Community Design Analysis.

[39] Jonas Oppenlaender, Kristy Milland, Aku Visuri, Panos Ipeirotis, and Simo Hosio. 2020. Creativity on Paid Crowdsourcing Platforms. In Proceedings of the 2020 CHI Conference on Human Factors in Computing Systems (CHI '20). Association for Computing Machinery, New York, NY, USA, 1-14. https://doi.org/10.1145/3313831.3376677 
[40] Juhani Pallasmaa. 2006. Eyes of the skin: Architecture and the senses. Academy Editions, London. https://oula.finna.fi/ Record/oula.501718www.wileyeurope.com ISSN: 07460554 Publication Title: Architect.

[41] Juhani Pallasmaa. 2014. Space, place and atmosphere. Emotion and peripherical perception in architectural experience. Lebenswelt: Aesthetics and Philosophy of Experience 0, 4 (July 2014), 230-245. https://doi.org/10.13130/2240-9599/4202

[42] Annemarie Ruijsbroek, Mariël Droomers, Peter P. Groenewegen, Wim Hardyns, and Karien Stronks. 2015. Social safety, self-rated general health and physical activity: Changes in area crime, area safety feelings and the role of social cohesion. Health and Place 31 (2015), 39-45. https://doi.org/10.1016/j.healthplace.2014.10.008

[43] Gillian M. Sandstrom, Neal Lathia, Cecilia Mascolo, and Peter J. Rentfrow. 2017. Putting mood in context: Using smartphones to examine how people feel in different locations. fournal of Research in Personality 69, C (2017), 96-101. https://doi.org/10.1016/j.jrp.2016.06.004

[44] Christine Satchell and Marcus Foth. 2011. Welcome to the jungle: HCI after dark. In Conference on Human Factors in Computing Systems - Proceedings. Association for Computing Machinery, New York, NY, USA, 753-762. https: //doi.org/10.1145/1979742.1979630 ISBN: 9781450302289.

[45] Susanne Schmidt, Frank Steinicke, Andrew Irlitti, and Bruce H Thomas. 2018. Floor-Projected Guidance Cues for Collaborative Exploration of Spatial Augmented Reality Setups. In Proceedings of the 2018 ACM International Conference on Interactive Surfaces and Spaces. Association for Computing Machinery, New York, NY, USA, 11.

[46] Avishag Shemesh, Gerry Leisman, Moshe Bar, and Yasha Jacob Grobman. 2021. A neurocognitive study of the emotional impact of geometrical criteria of architectural space. Architectural Science Review 64, 4 (July 2021), 394-407. https://doi.org/10.1080/00038628.2021.1940827

[47] Peter Sloterdijk. 2016. Spheres. Volume 3, Foams : plural spherology. Semiotext(e), South Pasadena, Calif. Publication Title: Semiotext(e) foreign agents series.

[48] Shenando Stals, Michael Smyth, and Oli Mival. 2019. UrbanixD: From ethnography to speculative design fictions for the hybrid city. In ACM International Conference Proceeding Series. Association for Computing Machinery, New York, NY, USA, 1-10. https://doi.org/10.1145/3363384.3363486

[49] Yuichiro Takeuchi. 2014. Towards Habitable Bits: Digitizing the Built Environment. In Proceedings of the Ninth ACM International Conference on Interactive Tabletops and Surfaces - ITS '14. ACM Press, Dresden, Germany, 209-218. https://doi.org/10.1145/2669485.2669506

[50] Michael Wessely, Ticha Sethapakdi, Carlos Castillo, Jackson C. Snowden, Ollie Hanton, Isabel P. S. Qamar, Mike Fraser, Anne Roudaut, and Stefanie Mueller. 2020. Sprayable User Interfaces: Prototyping Large-Scale Interactive Surfaces with Sensors and Displays. In Proceedings of the 2020 CHI Conference on Human Factors in Computing Systems. ACM, Honolulu HI USA, 1-12. https://doi.org/10.1145/3313831.3376249

[51] Jill Palzkill Woelfer, Amy Iverson, David G. Hendry, Batya Friedman, and Brian T. Gill. 2011. Improving the safety of homeless young people with mobile phones: Values, form and function. In Conference on Human Factors in Computing Systems - Proceedings. ACM Press, New York, New York, USA, 1707-1716. https://doi.org/10.1145/1978942.1979191

[52] Xiaoyi Yuan and Andrew Crooks. 2019. Assessing the placeness of locations through user-contributed content. In Proceedings of the 3rd ACM SIGSPATIAL International Workshop on AI for Geographic Knowledge Discovery, GeoAI 2019 (GeoAI 2019). Association for Computing Machinery, New York, NY, USA, 15-23. https://doi.org/10.1145/3356471. 3365231 ISBN: 9781450369572.

Received July 2021; revised September 2021; accepted September 2021 